\title{
Providing aesthetic by direct laminate veneer restorations of three patients with enamel defects at anterior region
}

\begin{abstract}
One of the most important aspects of modern dentistry is the restoration of the lost dental aesthetic of the patient. Over the years new treatment materials and methods for this purpose have emerged. Dentists generally prefer more conservative approaches such as laminate veneers instead of full ceramic crowns in anterior restorations, where aesthetic is important. Laminate veneers applied by two different methods, direct and indirect, are used to correct existing abnormalities, colorations and aesthetic defects. Direct composite laminate veneers based on the direct application of the composite resin in the clinic, which do not require a laboratory stage, are preferred due to their convenient cost and single seance finish.
\end{abstract}

Volume 8 Issue 6 - 2017

\author{
Suzan Cangul \\ Department of Restorative Dentistry, Dicle University, Turkey
}

Correspondence: Suzan Cangul, Department of Restorative Dentistry, Dicle University, 21280, Diyarbakir, Turkey, Email suzanbali@outlook.com

Received: November 03, 2017 | Published: November 10, 2017

Keywords: composite, laminate veneer, anterior aesthetic

\section{Introduction}

One of the most important aspects of today's dentistry is to restore the patient's natural appearance in addition to function and phonation. ${ }^{1}$ Color, shape, structure and position abnormalities of the teeth lead to important aesthetic problems for the patients. ${ }^{2}$ Often preferred methods for this purpose are prosthetic restorations. ${ }^{3}$ However, these restorations have many disadvantages, such as excessive preparation of teeth and damage of surrounding tissues such as gums. ${ }^{4}$ Dentists have gone directly to expand the indications of composite resin restorations, as patients' have increased demands for aesthetic restorations and their desire to protect healthy tooth structure. ${ }^{5}$ Together with improvements in modern adhesive techniques, the properties of composite resins have been increased and clinicians have introduced a safe and direct method to restore teeth. ${ }^{6,7}$ Thus, one of the basic goals of restorative dentistry is to complete the treatment of single seance anterior region with this method. Over the last decade, ongoing advances in composite resins, adhesive systems, and restorative techniques have led to significant improvements in aesthetic dentistry. ${ }^{8}$ The most important advantages of composite restorations are their minimum preparation size with their adhesive properties, their aesthetic appearance and strengthening the remaining tooth structure. ${ }^{9}$ Dental discolorations, fractures, caries lesions, and disorders in tooth alignment affect not only quality of life, but also aesthetic appearance and deterioration of the harmony in the smile. ${ }^{9,10}$ Direct composite veneers used to restore the aesthetics of damaged teeth for this purpose are good treatment options. ${ }^{11}$ Laminate veneers are restorations designed to correct existing abnormalities, aesthetic disorders and color changes. ${ }^{12}$ The main indications for these restorations are colored teeth, chronical fractures, palatal position teeth, congenital or acquired malformations, rotational teeth, diastemas, colorless restorations, absence of lateral incisors, abrasions and erosions. ${ }^{1-3}$ These restorations, which offer quite good aesthetic results, are based on the principle that a composite resin is applied directly to the tooth surfaces. when compared with prosthetic approaches and indirect laminate veneer except for the necessity of tooth preparation, this technique is very cost, the treatment is reversible and an additional adhesive system is not required. ${ }^{13,14}$
The irregular morphology of the enamel causes serious problems in the aesthetic appearance. ${ }^{15}$ Treatment options are determined by the severity of the loss of enamel. In these studies, three patients who applied to our clinic with loss of enamel were restored with a direct composite laminate veneer.

\section{Case reports}

Three patients with enamel defects in the lower and upper teeth of the anterior region were referred to the Restorative Dental Treatment Clinic of Faculty of Dentistry, Dicle University. Clinical and radiological examinations were performed after the patient's anamnesis was obtained. As a result of these examinations, periodontal tissue was found to be healthy and not to be a pathological symptom. The patient was informed about the causes of the problem and treatment options. The patients did not accept an excess preparation in their teeth, so direct composite laminate veneer restoration which is a more conservative treatment option was decided. After the initial photographs of the patients were taken, the colored teeth of patients due to habits such as tea, coffee, and smoking were cleaned first. After cleaning, tooth colors were determined using a scale. Cotton rolls were placed to ensure isolation and patients were made ready for treatment. First, guide grooves were opened with a fissure bar under water cooling. Then, these grooves were prepared using a chamfer bur as to be $0.5 \mathrm{~mm}$ in depth, $0.2 \mathrm{~mm}$ in the mesial and distal contact points, and $0.3 \mathrm{~mm}$ in the gingival step. $37 \%$ orthophosphoric acid (Vococid; Vocos, Cuxhaven, Germany) was applied for $15 \mathrm{sec}$ at dentin and 30 $\mathrm{sec}$ at enamel surfaces. The all in one bonding agent (Adper Single Bond, 3M ESPE, USA) was applied to all prepared surfaces according to the manufacturer's instructions with a brush, dried with lightly air, then polymerized for $10 \mathrm{sec}$ using a LED light source. Before composite restoration, color evaluations were performed again and the first layer was polymerized by placing the opaque resin in order to avoid dark color reflections in the palatinal regions. Subsequent layers were finished with composite resin (Gradia Direct) using incremental technique, each layer was polymerized for 40 seconds. In the same way, gaps between teeth were closed after transparent bands were 
placed in the gingiva with sufficient convexity. The surplus in the restored teeth was removed with micro-granular flame-tipped drills and polished using Sof-lex (3M dental products) discs. After that, the patient was taken to the control after 6 months (Figures 1-4).
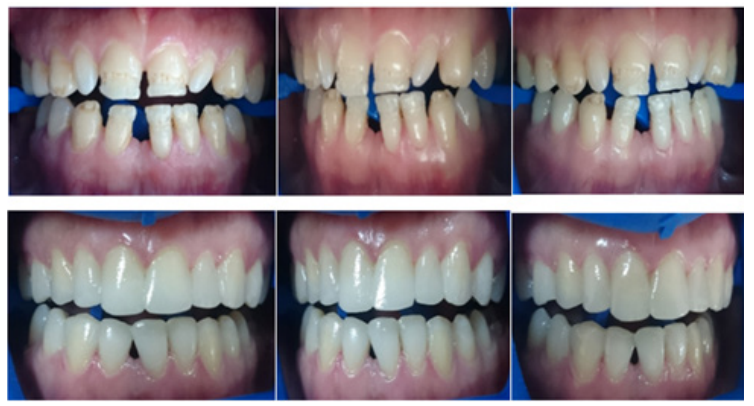

Figure I Comparison of beginning and ending photographs of the first patient from different angles.
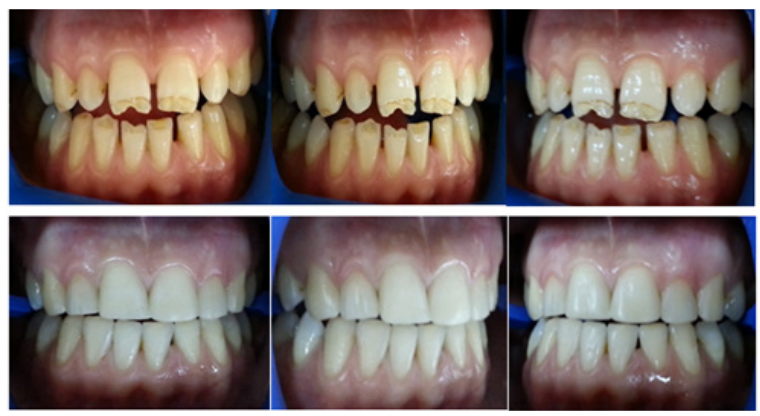

Figure 2 Comparison of beginning and ending photographs of the second patient from different angles.
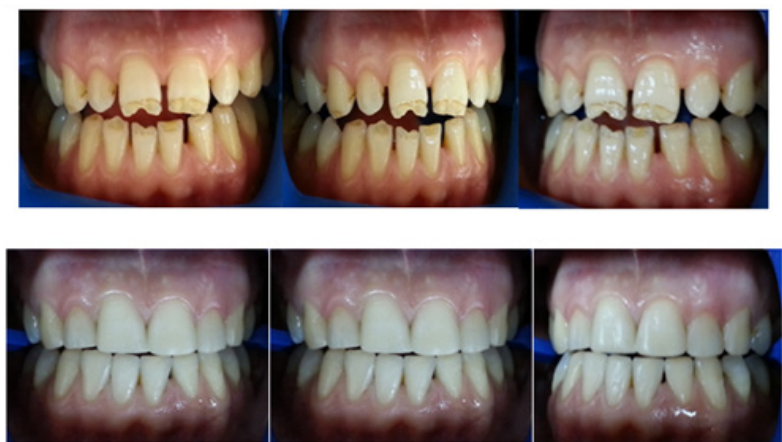

Figure 3 Comparison of beginning and ending photographs of the third patient from different angles.
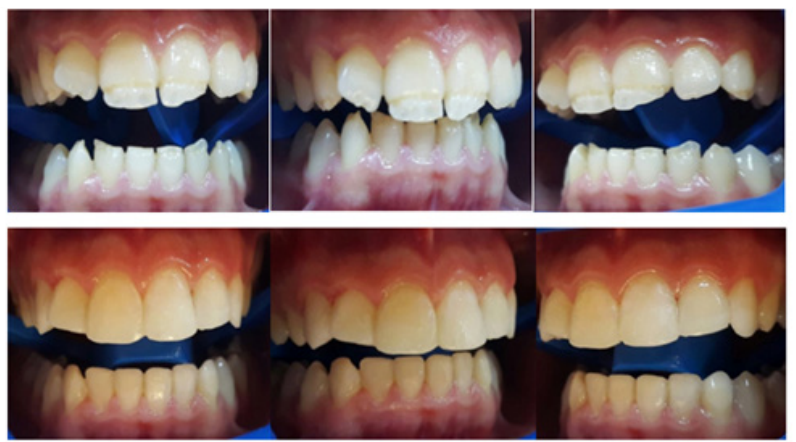

Figure 4 Comparison of beginning and ending photographs of the third patient from different angles.

\section{Discussion}

Today, the success of dental treatments has greatly increased with improvements in aesthetic materials. In order to perform treatment with a minimum preparation in the anterior region, natural-looking laminate veneer restorations that meet the aesthetic needs of patients have been developed. ${ }^{16}$ Laminate veneer restorations, which have become treatment alternatives for aesthetic problems in recent years, are applied in two forms, direct and indirect. ${ }^{2-12}$ Deciding between the two methods, factors such as time, social and cost are the factors are considered.Direct laminate veneers which don't require laboratory stage, have advantages such as immediate aesthetic result, low cost, good marginal compatibility and reversible treatment. ${ }^{17,18}$ Indirect laminate veneers have disadvantages such as high costs, irreversible treatment, long time taking and additional cementation procedure. ${ }^{19}$ The positive properties of composite resins, such as different color options, easy application, good durability, and low solubility in the mouth, have increased the superiority of direct laminate veneers. ${ }^{20}$ Also composite laminate veneers have been extensively researched and supported with various clinical and laboratory studies. ${ }^{21,22}$ There are also long follow-up studies on these restorations. We also performed direct laminate veneer restorations on the anterior teeth of three patients with enamel hypoplasia at the request of the patients. Likewise, diastemas were also closed by this treatment method.

\section{Result}

Although direct laminate veneers have some disadvantages such as coloration and fragility, they have become a good treatment option in the aesthetic problems of anterior teeth for patients because of the advantages of new composite resins. The satisfaction of patients after treatment is the greatest indication of this.

\section{Funding}

None.

\section{Acknowledgments}

None.

\section{Conflicts of interest}

None.

\section{References}

1. Zorba YO, Ercan E. Clinical evaluation of composite laminate veneers applied directly: presentation of two cases. SU Faculty of Dentistry Journal. 2008;17:130-135.

2. Yüzügüllü B, Tezcan S. Comparison of indications of laminate veneer restoration options for color change and enamel eroded teeth. CU Faculty of Dentistry Journal. 2005;8:133-137.

3. Hickel R, Heidemann D, Staehle HJ, et al. Direct composite restorations extended use in anterior and posterior situations. Clin Oral Invest. 2004;8(2):43-44.

4. Aristidis GA, Dimitra B. Five-year clinical performance of porcelain laminate veneers. Quint Int. 2002;33(3):185-189.

5. Deliperi S, Bardwell DN, Congiu MD. Reconstruction of severely damaged endodontically treated and bleached teeth using a microhybrid composite resin: two-year case report. Pract Proced Aesthet Dent. 2003;15(3):221-226 
6. Terry D. Adhesive reattachment of a tooth fragment: the biological restoration. Pract Proced Aesthet Dent. 2003;15(5):403-409.

7. Adanir N, Ok E, Erdek Y. Re-attachment of subgingivally oblique fractured central incisor using a fiber post. Eur J Dent. 2008;2(2): 138141.

8. Meyenberg K. The ideal restoration of endodontically treated teeth structural and esthetic considerations: a review of the literature and clinical guidelines for the restorative clinician. Eur $J$ Esthet Dent. 2013;8(2):238-268.

9. Prieto LT, Araujo CT, De Oliveira DC, et al. Minimally invasive cosmetic dentistry: smile reconstruction using direct resin bonding. Gen Dent. 2014;62(1):e28-e31.

10. Sadowsky DJ. An overview of treatment considerations for esthetic restorations: a review of the literature. J Prosthet Dent. 2006;96(6):433442.

11. Gresnigt MM, Kalk W, Ozcan M. Randomized controlled split-mouth clinical trial of direct laminate veneers with two micro-hybrid resin composites. J Dent. 2102;40(9):766-775.

12. Özdemir E, Agüloğlu S, Değer Y. Aesthetic rehabilitation of three patients with enamel defects in front of their teeth using composite and porcelain laminate veneers (case report). GU Faculty of Dentistry Journal. 2009;26:171-176.

13. Hemmings WK, Darbar UR, Vaughan S. Tooth wear treated with direct composite restorations at an increased vertical dimension: Results at 30 months. J Prosthet Dent. 2000;83(3):287-293.
14. Wilson NHF, Mjör IA. The teaching of Class I and Class II direct composite restorations in European dental schools. J Dent. 2000;28(1):15-21.

15. Williams WP, Becker LH. Amelogenesis imperfecta: functional and esthetic restoration of a severely compromised dentition. Quintessence Int. 2000;31(6):397-403.

16. Col DSJ D'Souza, Kumar M. Esthetics and Biocompatibility of Composite Dental Laminates. MJAFI. 2010;66(3):239-243.

17. Marco MMG, Warner K, Mutlu Ö. Randomized controlled split-mouth clinical trial of direct laminate veneers with two micro-hybrid resin composites. J Dent. 2012;40(9):766-775.

18. Mainak KS, Suparna GS. Restoration of anterior teeth with direct composite veneers in Amelogenesis Imperfecta. International Journal of Dental Clinics. 2011;3(2):99-100.

19. Bağiş B, Bağiş HY. Clinical application stages of porcelain laminate veneers: A clinical case report AU Faculty of Dentistry Journal. 2006;33:49-57.

20. Bagis B, Aydoğan E, Bagis HY. Direct Restorative Treatment of Missing Maxillary Laterals with Composite Laminate Veneer: A Case Report. Open Dent J. 2008;2:93-95.

21. Izgi AD, Ayna E. Direct restorative treatment of peg-shaped maxillary lateral incisors with resin composite: a clinical report. J Prosthet Dent. 2005;93(6):526-529.

22. Stappert CF, Ozden U, Gerds T, et al. Longevity and failure load of ceramic veneers with different preparation designs after exposure to masticatory simulation. J Prosthet Dent. 2005;94(2):132-139. 